\title{
ALGUMAS REFLEXÕES SOBRE O MÉTODO FUNCIONAL NO TRABALHO DA ENFERMAGEM
}

\author{
Roseney Bellato* \\ Maria José Pasti ** \\ Elizabete Takeda***
}

BELLATO, R.; PASTI, M.J.; TAKEDA, E. Algumas reflexões sobre o método funcional no trabalho da enfermagem. Rev.latino-am.enfermagem, Ribeirão Preto, v. 5, n. 1, p. 75-81, janeiro 1997.

Neste trabalho buscamos fazer urna reflexão acerca da adoção do método funcional no trabalho da enfermagem, bem como uma crítica a esse mesmo modelo. Tentamos também, evidenciar como a equipe de enfermagem e, principalmente as enfermeiras, vem "subvertendo" esse modelo no seu quotidiano de trabalho.

UNITERMOS: enfermagem, método funcional

\section{INTRODUÇÃO}

Enquanto mestrandas da Área de Enfermagem Fundamental da Escola de Enfermagem de Ribeirão Preto - USP e cursando a disciplina "Análise Crítica da Assistência de Enfermagem", tivemos oportunidade de refletir sobre a prática de enfermagem calcada no método funcional, ao mesmo tempo em que repensávamos nossa atuação profissional como enfermeiras, dentro desse modelo. Tendo como ponto de partida essa reflexão inicial, resolvemos buscar maior embasamento para uma análise um pouco mais aprofundada, trazendo subsídios da história não só da enfermagem, mas também da instituição hospitalar e da adoção do método funcional como forma de organização do trabalho da enfermagem.

Tal análise busca lançar luz às nossas inquietações quanto a fragmentação que tem ocorrido na assistência de enfermagem, que parece resultar em prejuízo tanto aos indivíduos para quem ela se destina como para seus próprios prestadores. Porém, nos parece que, mesmo tendo adotado amplamente esse sistema de divisão do trabalho, a enfermagem tem se mostrado insatisfeita com ele, e tem procurado formas de tomar menos fragmentada possível essa assistência, visto que esse método se opõe a crença que a enfermeira tem de uma assistência holística ao ser humano. Assim, também pretendemos comentar neste trabalho algumas das contradições que se colocam no que se refere a adoção do método funcional na organização do trabalho da enfermagem e algumas das concepções da enfermeira acerca de como deveria ser prestado o cuidado.

Salientamos que não é nossa pretensão propor soluções para o problema aqui colocado mas sim, suscitar a discussão entre as enfermeiras, visto que a proposição de soluções envolve grandes mudanças não só organizacionais, mas também filosóficas, tanto no que se refere a enfermagem quanto as instituições de saúde, bem como um profundo engajamento dos sujeitos que pretendem propor as soluções.

\section{SURGIMENTO DO HOSPITAL COMO INSTITUIÇÃO DE SAÚDE}

Se a doença acompanha o ser humano desde seus primórdios, a necessidade do cuidado ao ser doente seguiu o mesmo trajeto. Assim, todas as cidades em todas as épocas, mobilizaram-se para responder a essa necessidade. Templos, conventos e mosteiros já se prestaram a esse fim, recebendo os doentes e

\footnotetext{
* Docente do Departamento de Enfermagem Médico-Cirúrgica da Universidade Federal de Mato Grosso, mestranda na Área de Enfermagem Fundamental da Escola de Enfermagem de Ribeirão Preto da Universidade de São Paulo

** Enfermeira do Hospital das Clínicas da Faculdade de Medicina de Ribeirão Preto e mestranda da Área de Enfermagem Fundamental da Escola de Enfermagem de Ribeirão Preto da Universidade de São Paulo

*** Professor Auxiliar do Departamento de Assistência de Enfermagem Hospital ar da Faculdade de Medicina do Triângulo Mineiro - UberabaMG, mestranda na Área de Enfermagem Fundamental da Escola de Enfermagem de Ribeirão Preto da Universidade de São Paulo
} 
providenciando-lhes atenções especiais, cujo intuito era, não apenas o cuidado com o corpo, mas também com a alma do enfermo. Tal situação se mostrou particularmente presente durante toda a Idade Média, quando se partilhava a convicção de que a assistência espiritual era o remédio mais indicado em casos de doenças e de outros infortúnios.

Até o século XVIII, conforme cita FOUCAULT (1993) "o hospital era essencialmente uma instituição de assistência aos pobres. Instituição de assistência, como também de separação e exclusão. O pobre como pobre tem necessidade de assistência e, como doente, portador de doença e possível contágio, é perigoso. Por estas razões, o hospital deve estar presente tanto para recolhê-lo, quanto para proteger os outros do perigo que ele encarna". As atividades desenvolvidas dentro dessa instituição cabiam a religiosos ou leigos, geralmente mulheres, que as executavam com vistas ao salvamento de suas almas mediante ações de caridade. A construção dos hospitais se dava sempre fora da zona urbana visto sua característica de segregação social.

No Período Renascentista, o hospital aos poucos se desliga da influência religiosa para então caracterizarse como instituição social sob responsabilidade do Estado. ANTUNES (1985) afirma que, como fruto de diversas transformações ocorridas, sobretudo no século XVIII, acreditou-se que os hospitais pudessem vir a exercer uma ação terapêutica efetiva e potencialmente eficaz sobre os doentes internados caso superassem suas condições insalubres, pois a sujeira, a promiscuidade e a mistura dos corpos em camas coletivas, favoreciam toda ordem de contágios.

Até esse momento, o hospital e a medicina seguiram campos independentes, visto que o cuidado aos doentes dentro da instituição hospitalar se baseava em cuidados com as feridas, preparo de chás e alimentação, cuidados estes exercidos por leigos. Conforme coloca ALMEIDA (1984), "é no fim do século XVIII que o saber médico passa a ocupar espaço no hospital e introduz mecanismos disciplinares vindos da organização militar, a fim de anular os seus efeitos negativos". Porém, a situação de insalubridade dentro dos hospitais vai persistir até a metade do século XIX, quando essa situação começa a se modificar com 0 estabelecimento da bacteriologia por Pasteur e os conceitos de assepsia de Lister. Nesta época também surge a personagem mais importante da história da enfermagem moderna, Florence Nightingale trazendo novas perspectivas para essa profissão e para o próprio cuidado à saúde.

Assim, o hospital começa a transformar-se em local de cura, onde o médico exercerá seu trabalho sobre o doente e a doença, buscando produzir a cura, e as práticas médicas e de enfermagem, antes independentes, encontram-se a partir daí no mesmo espaço. Também se torna inadiável a necessidade de anular os efeitos negativos da instituição hospitalar, para que a cura seja favorecida. Dentro dessa perspectiva, o hospital sofre sérias e profundas mudanças, que ampliam enormemente sua complexidade, até chegar neste hospital atual, onde "a meta primordial é os cuidados médicos, cuja provisão é norteada por normas científico-tecnológicas e por requisitos de racionalidade e economia organizacional" (TREVIZAN, 1988).

\section{ORGANIZAÇÃO HISTÓRICA DO TRABALHO DA ENFERMAGEM}

A enfermagem é uma atividade tão antiga quanto $o$ ser humano, tendo nascido de suas necessidades de cuidados com a saúde e a doença. Assim, nas comunidades primitivas, o cuidado de enfermagem aparece intimamente relacionado à magia e ao sobrenatural, visto que as doenças eram atribuídas aos deuses. Dentro dessa perspectiva, ANGERAMI \& CORREIA (1989) afirmam que a enfermagem consistia na arte de manipular as forças da natureza e das divindades para a saúde do homem e das comunidades. Nas civilizações antigas ainda permanece o enfoque místico tanto para a doença como para o seu cuidado. À mulher, por dar à luz, cuidar de sua prole, lidar com a agricultura e conhecer o segredo das plantas, cabia assegurar a manutenção da vida e, conseqüentemente, cuidar dos doentes, idosos e moribundos.

A partir de Hipócrates, os misticismos e superstições são substituídos pelo diagnóstico e tratamento médico, onde a cura visa propiciar condições ao ser humano para readquirir seu equilíbrio. Porém, esse processo de cura é permeado de atividades de cuidado ao ser doente, e estas ficam a cargo das mulheres.

Durante todo período cristão e medieval, o cuidado ao ser doente toma uma conotação de atividade caritativa, com vistas ao salvamento da alma do doente e de quem dele cuidava. Assim, juntamente com outros elementos das ordens religiosas, "surgem as diaconisas, as quais eram ordenadas para o serviço, o qual consistia em atender as necessidades de sobrevivência das pessoas carentes e doentes" (ANGERAMI \& CORREIA, 1989).

$\mathrm{Na}$ idade moderna, a enfermagem assume dois rumos, ou seja, em um deles permanece ligada à luz da caridade cristã e da vocação religiosa e em outro, pouco a pouco vai evoluindo para a profissionalização, embora ambas se mantenham ainda dentro de bases empíricas, que persistirão até a primeira metade do século XIX.

A partir da segunda metade do século XIX, com Florence Nightingale, a enfermagem se transforma radicalmente, buscando racionalizar sua prática, através de um trabalho calcado em bases mais científicas, que vão Ihe dar a configuração profissional necessária. Florence 
Nightingale encontrou o hospital com condições precárias para a promoção da cura devido a pouca higiene e grande promiscuidade aí presentes, o que favoreceu a entrada da enfermagem em cena, numa forma de buscar a normalização e a regulamentação, bem como a organização do espaço terapêutico do doente. Para tanto, Florence legitima uma hierarquia institucional, preparando enfermeiras para ocuparem posições de chefia em enfermarias e superintendência, bem como treinando aprendizes para o cuidado propriamente dito, as primeiras sendo denominadas lady-nurses por possuírem alta posição social, e as que prestavam o cuidado direto as nurses, de nível social inferior. Os hospitais passam a ser considerados como espaço terapêutico para a cura, onde se privilegia, principalmente, a relação médico-paciente, sendo que as demais profissões passam a ser vistas como as que fornecem suporte infra-estrutural para que 0 trabalho 2 médico e, conseqüentemente a cura, se dêem.

Assim, duas dicotomias importantes se fazem sentir nesse momento: a separação entre cura (do médico) e cuidado (da enfermagem) e entre o administrar (das lady-nurses) e o cuidar (das nurses), ambas com repercussões sérias para o futuro da enfermagem.

\section{O MÉTODO FUNCIONAL ADAPTAÇÃO NA ENFERMAGEM}

O ser humano sempre necessitou do seu trabalho para sua sobrevivência. Este trabalho evoluiu das formas mais simples e individual de execução, passando pelo trabalho coletivo, porém sem especialização, até períodos mais recentes, onde a sua complexidade levou a divisão extrema, associada ao alto grau de especialização de seus executores. Com esse aumento na complexidade e sub-divisão quase infinita do trabalho, tornou-se necessário organizá-lo deforma a atender a essa nova modalidade de produção. Assim, buscou-se formas para sua organização, baseadas nas influências de cada época sendo as principais, a adoção da hierarquia da autoridade como na Igreja Católica, no princípio de comando e da hierarquia como nas organizações militares, a influência dos economistas liberais baseada na livre concorrência onde a tônica do processo produtivo passa a seraracionalização do trabalho, etc. Porém, nenhuma influência foi tão decisiva como a das primeira e segunda Revoluções Industriais, "onde as oficinas são substituídas pelas fábricas, os homens pelas máquinas. Há o aumento da produção com a baixa dos preços e o conseqüente aumento do consumo. Nas fábricas começa a demanda de pessoal preparado para atender a essa nova modalidade de produção" (KURCGANT, 1991). Para responder a essa nova realidade, buscou-se formas denominadas científicas de organização do trabalho.

É dentro dessa ótica que surgiu a Teoria Científica da Administração, cujo maior representante foi Frederick Winslow Taylor (1856 - 1915) que trazia, juntamente com seus seguidores, a proposta básica de aumento da produção pela eficiência do nível operacional. "Para tanto, preconizavam a divisão do trabalho, a especialização dos operários e a padronização das atividades e tarefas por eles desenvolvidas. Assim, o operário passava, a saber, cada vez menos do todo que constituía seu trabalho, para passar, a saber, cada vez mais a respeito da parte que Ihe cabia" (KURCGANT, 1991). Toda a base científica dessa teoria foi dada através dos estudos de tempo e movimento que visavam a padronização das tarefas, bem como o tempo necessário para desenvolvê-las, além de estudos para a adequação do ambiente físico ao trabalho. A supervisão funcional também passa a ter papel primordial na administração científica, visto que, com a especialização do operário e a perda da visão do todo, torna-se necessário buscar-se os elos de ligação entre as partes e esse todo. Este supervisor está imbuído da chamada autoridade funcional.

Contemporâneo de Taylor, Henry Fayol (1841 1925) cria a Teoria Clássica da Administração, que tem suas premissas básicas calcadas na estrutura administrativa da empresa, valorizando sobremaneira a autoridade, a responsabilidade, a disciplina, a unidade de comando e de direção e a subordinação do interesse particular ao interesse geral, dentre outros princípios. Sob influência das estruturas eclesiásticas e militares, concebe a organização como uma estrutura rigidamente hierarquizada, estática e limitada, onde a divisão horizontal do trabalho é representada pelo agrupamento de atividades afins ou departamentalização. Na linha vertical da hierarquia, estabelece normas e regras rígidas a serem seguidas pelos administradores.

A amarração da rigidez empresarial que se formou com as duas teorias anteriores, foi completada por Max Weber (1864 - 1920) e sua Teoria Burocrática, que enfatizou a racionalidade, ou seja, a adequação dos meios utilizados nas organizações com vistas a atingir os resultados esperados. Sua maior influência passou a ser sentida mais fortemente a partir de 1940, com o aumento na complexidade das organizações e a conseqüente necessidade de serem buscadas novas formas de controle de pessoal. Com isso, se detalhou pormenorizadamente como as coisas deveriam ser feitas, exigindo também um treinamento minucioso do operário. A impessoalidade nas relações humanas é um ponto importante a ser considerado, e o apego às regras, normas e regulamentos passou a dar o tom dessa impessoalidade.

Com a enfermagem inserida no hospital e com o aumento crescente da complexidade hospitalar, esta instituição torna-se uma empresa prestadora de serviços, 
onde a divisão de trabalho sofre enorme influência dos modelos administrativos preponderantes.

FERRAZ (1990) afirma que, a grande divisão do trabalho faz-se entre os que pensam e, portanto, administram e concebem, e os que executam, os administrados. Essa é a forma como está organizada a divisão do trabalho na enfermagem, cabendo primordialmente à enfermeira as ações administrativas e de educação, atividades essas consideradas intelectuais. Às demais categorias, atendentes, auxiliares e técnicos de enfermagem, competem ações assistenciais. Dessa forma, fica estabelecida a divisão do trabalho na enfermagem de acordo com a especialização de seus membros.

Outra característica "herdada" do taylorismo pela enfermagem é a valorização do "como fazer" em detrimento ao "porque fazer", especificado nos manuais de normas, rotinas e procedimentos técnicos que trazem descrições detalhadas dos passos a serem seguidos nas atividades desenvolvidas, bem como dos agentes que devem desempenhá-las. Isso se mostra presente também nas escalas diárias de divisão de tarefas. A divisão hierárquica rígida dentro do trabalho da enfermagem também é um traço importante dessas teorias administrativas, assim como a valorização do quantitativo em detrimento do qualitativo e a pouca relevância às relações interpessoais.

Porém, apesar de todos esses "ranços" ainda fortemente presentes na enfermagem, percebe-se uma "subversão" velada à esses princípios herdados das teorias administrativas mencionadas, que está presente, de forma implícita ou explícita, na sua filosofia do cuidar.

\section{CONTRADIÇÕES ENTRE O MÉTODO DE TRABALHO NA ENFERMAGEM E SUA FILOSOFIA}

\section{Visão holística do homem $x$ divisão do trabalho em tarefas}

A enfermagem moderna, nascida com Florence Nightingale na segunda metade do século XIX, já trouxe em seu bojo a divisão técnica do trabalho, onde as ladies nurses se encarregavam da administração da enfermagem e as nurses ficavam responsáveis pelo cuidado de enfermagem. Porém, com o tempo e o aumento na complexidade da instituição hospitalar e, conseqüentemente da enfermagem, a divisão entre o administrar e o cuidar tornou-se insuficiente.

Como ressalta ALMEIDA (1984), a técnica de enfermagem começou a se organizar como meio de trabalho em enfermagem, não tanto para dar conta do objeto de trabalho, ou seja, prestar o cuidado de enfermagem, mas para dar conta da grande demanda destes cuidados devido ao maior número de internações, pelo aumento do número de hospitais e pelo maior fluxo de pacientes devido ao menor tempo de internação. $\mathrm{E}$ ainda, o emprego de um grande número de pessoal de enfermagem sem preparo, necessitando, portanto, de simples instrução dada passo por passo sobre a maneira de executar um procedimento, mas sem necessidade de aprender o porquê de tal procedimento veio ao encontro daquela necessidade.

Dessa forma, o cuidado de enfermagem, que inicialmente era executado de maneira integral por uma pessoa (mesmo que leiga), passa a ser fragmentado em "técnicas" ou "tarefas", que vão possibilitar o desenvolvimento da prática de enfermagem denominada funcional, que visa economia de tempo e maior agilidade na execução do serviço. Dentro desse sistema, os cuidados a serem prestados aos pacientes são distribuídos entre os elementos da equipe de enfermagem que, supostamente, tenham competência técnica para executá-lo, visto que as tarefas são divididas por grau de complexidade, fazendo com que um mesmo paciente seja atendido por vários elementos da enfermagem.

Por estranha contradição, a enfermagem, embora empregue na maioria dos serviços de saúde o método funcionalista de trabalho, mantém a crença de que deve prestar o cuidado de enfermagem de maneira holística, sem compartimentalizar o homem em segmentos estanques, mas vendo-o em sua totalidade de ser biopsico-sócio-espiritual. Inúmeros trabalhos de enfermeiras, entre eles podemos citar o de PATRÍcIO (1990), nos mostram que essa preocupação está presente no processo de cuidar da enfermeira.

Assim, a enfermeira se debate na busca de uma forma de organização do trabalho, não pela divisão deste em tarefas, que traz consigo a divisão do ser humano em partes, mas pelo cuidado de enfermagem prestado de forma integral, e onde a qualidade desse cuidado seja mais importante do que a padronização dos procedimentos.

\section{Dicotomia entre o pensar (concepção do cuidado) e o fazer (execução do cuidado)}

Da mesma forma que o método funcional na enfermagem colaborou com a fragmentação do trabalho em tarefas, dicotomizou também o ato de conceber e o de executar o cuidado. Visto ser a enfermagem subdividida em categorias com nível de preparo técnico e intelectual diversificado, isto favoreceu tal dicotomia, ficando as categorias com maior preparo educacional e técnico incumbidas da concepção e administração do cuidado, cabendo às categorias com menor preparo executar o cuidado concebido por outrem. Dessa forma, ocorre na enfermagem uma divisão do trabalho tanto a nível 
horizontal (em tarefas), quanto vertical (em categorias).

Com a fragmentação do trabalho ocorrida na enfermagem, as categorias profissionais subalternas à enfermeira se distanciam do todo, que é o cuidado de enfermagem, para se fixar nas partes, que são as tarefas, ficando sua atuação profissional reduzida a um "que fazer" rotineiro e desmotivador.

A enfermeira por sua vez, sente a inadequação entre sua formação profissional (que privilegia a assistência direta e o gerenciamento dessa assistência) e as funções que o mercado de trabalho espera que ela cumpra (mais voltadas para o controle burocrático da instituição). Acresce-se a isso, conforme salienta PAIM (1979), que os hospitais tradicionais, normativos e rotineiros por excelência, superestruturado e verticalizado em sua hierarquia, de organização fechada e por isso pouco participativa, impede o desempenho da enfermeira em níveis mais autônomos.

Nessa perspectiva, a motivação para a realização do trabalho parece sofrer um profundo abalo, visto que os fatores que dão sustentação a essa motivação não se encontram presentes. Como assinala Herzberg apud HAMPTON (1990) em sua Teoria da Motivação, alguns dos fatores que devem estar presentes para que ocorra essa motivação em situação de trabalho são: realização, reconhecimento, o trabalho em si, responsabilidade, avanço e crescimento. Observa-se que são fatores interrelacionados e intrínsecos ao próprio trabalho e, aparentemente, inconciliáveis com um trabalho fragmentado, onde haja perda da visão do todo.

\section{Administração rigidamente hierarquizada $x$ concepção moderna de gerenciamento}

KURCGANT (1991) assinala que, "nas instituições de saúde, a estruturação rigidamente hierarquizada estabelece a subordinação integral de um indivíduo a outro, e de um serviço a outro. A enfermagem como um desses serviços, reproduz na sua estrutura o modelo maior". Isso se toma mais evidente quanto maior e mais complexa for a instituição de saúde, pois esta, sendo considerada como uma empresa, terá seu desenvolvimento organizacional situado em uma das cinco fases propostas por Greiner apud CHIAVENATO (1987), quais sejam, fase pioneira, de expansão, de regulamentação, de burocratização ou de reflexibilização.

Dessa forma, se observa que de modo geral, as instituições têm o seu desenvolvimento organizacional acompanhado de uma rigidez crescente no estabelecimento de normas e rotinas institucionais, que caminham para uma verdadeira rede de regulamentação burocrática, pautada na especialização dos indivíduos, e cuja característica principal é uma forte impessoalidade nas relações e pouquíssima flexibilidade. Tal situação pode culminar comum a reavaliação organizacional, que buscará uma readaptação à flexibilidade e um reencontro com a capacidade inovadora perdida.

$\mathrm{Na}$ nossa realidade, ainda temos a grande maioria das instituições de saúde, e dentro delas a enfermagem; na fase de aumento da complexidade burocrática. Dentro dessa perspectiva, ANSELMI (1989) coloca que, "estas estruturas vem sendo bastante questionado, porquê não tem conseguido dar respostas efetivas às transformações que rapidamente ocorrem, seja em relação ao conhecimento de novos processos e tecnologias, às reivindicações dos trabalhadores no sentido de maior participação na gestão do trabalho". Buscam-se assim, propostas no sentido da construção de estruturas administrativas mais flexíveis, participativas e descentralizadas.

Nessas instituições, as hierarquias de mando, muita vezes inflexíveis, levam os indivíduos a buscar, no seu quotidiano de trabalho, formas de "subverter" o poder delas advindo, não de forma direta, mas através do que MAFFESOLI (1984) chama de "astúcia contra as imposições normativas... (onde) os diferentes grupos podem mais ou menos aceitá-las sem, no entanto, interiorizá-las e tomá-las para si". Assim, institui-se o "jeitinho", o "faz de conta que faz, mas não faz", numa tentativa de tornar mais "humanizada" a instituição.

\section{Produtividade $\mathrm{x}$ qualidade da assistência de enfermagem}

A instituição de saúde sendo vista como uma empresa prestadora de serviços, traz atrelada a si o conceito de produtividade. Este conceito, utilizado tanto como sinônimo de aumento da produção, como o incentivo dado aos indivíduos dentro de uma empresa em decorrência desse aumento, é visto pelos administradores como um objetivo a ser atingido. Isso fica claro no documento elaborado pelo BRASIL/MEC/SENESU/DHERM (1992) quando ressaltam que "a constatação de que a produtividade dos serviços de saúde deixa muito a desejar, faz com que os administradores públicos e privados em saúde busquem fórmulas para incrementar a efetividade dos serviços. O incentivo à produtividade como um mecanismo de gestão de recursos humanos, aplicado à remuneração básica estimula ao prestador ou equipe de serviço a aumentar sua produção por insumos, sem perda da qualidade". Se a enfermagem dentro da instituição de saúde tem por objeto de trabalho o cuidado à saúde, este não pode ser reduzido a simples somatória de técnicas e procedimentos quantificáveis, onde se busque apenas a execução de um maior número de tais procedimentos dentro do menor tempo possível.

$\mathrm{O}$ ato de cuidar tem nuances qualitativas próprias, que envolvem relação interpessoal, traços culturais, 
valores individuais, que não podem ser reduzidos a dados mensuráveis. Tal singularidade deve ser considerada em toda a sua extensão pelos administradores, para que a qualidade da assistência de enfermagem a ser prestada não seja desprezada em prol da quantidade de procedimentos a serem feitos. Acresce-se a isso, o fato de que a qualidade da assistência de enfermagem deve ser considerada não apenas do ponto de vista da instituição ou de seus prestadores, mas também do cliente, que deve ser o alvo dessa assistência.

\section{Isso nos leva a pensar que...}

A enfermagem ainda está em busca de seu "espaço no mundo", evidenciado por essa insatisfação que experimenta no trabalho fragmentado e desvinculado da totalidade do ser humano, pela tendência em considerar o cuidar feminino perdido como sendo seu verdadeiro objeto de trabalho, bem como pela busca de visibilidade e de reconhecimento dentro da equipe de saúde. A inquietação da enfermeira com os modelos de cuidado à saúde (melhor seria dizer de cura à doença) mostram que, longe de ser a profissional alienada e submissa que se propala, é alguém que está em constante busca por modelos mais humanizados de assistência de enfermagem.

Essa profunda inquietação que se observa na enfermeira tem um eco maior nas ciências que, insatisfeitas.com o paradigma vigente, vêem o mundo ainda sob um prisma mecanicista e determinista, buscam um novo e emergente paradigma que tenta resgatar a dimensão holística do ser humano, vendo-o como parte integrante e indissociável do universo.

Dentro dessa perspectiva, a "visibilidade" que a enfermagem busca parece já estar sendo sentida por elementos externos a ela, como é o caso de CAPRA (1992), que afirma que a assistência ao ser humano de forma global "está sendo hoje vigorosamente advogada por enfermeiras que se encontram na vanguarda do movimento balística de saúde. Um número crescente de enfermeiras está decidindo ser terapeuta independente, em vez de mera assistente de médicos, procurando orientar-se em sua prática por uma abordagem balística. Essas enfermeiras, assim educadas e motivadas, serão as mais qualificadas para assumiras responsabilidades da clínica geral. Elas estarão aptas a fornecer a educação e o aconselhamento necessários à saúde e a avaliar a dinâmica da vida dos pacientes, o que pode servir de base para a assistência sanitária preventiva".

Assim, cabem principalmente a nós, profissionais enfermeiras, refletirmos sobre esse nosso "profético destino" e buscarmos formas de tirá-lo dessa concepção aparentemente quimérica, para transformálo em realidade.

\section{SOME REFLEXIONS ABOUT THE FUNCTIONAL METHOD IN NURSING WORK}

The main target of the present essay is to carry out a reflex ion on the adoption of the functional method in nursing work, as well as on the criticism to this method. A secondary aim will be to show how the nursing team has been "using" this method in their daily work routine in the search for a more humanized nursing care.

KEY WORDS: nursing, functional method

\section{ALGUNAS REFLEXIONES SOBRE EL MÉTODO FUNCIONAL AUN VIGENTE EN EL TRABAJO DE LA ENFERMERÍA}

En este trabajo buscamos hacer una reflexión sobre la adopción del método funcional en el trabajo de la enfermería así como hacer una crítica a este mismo método. Buscamos también evidenciar como el equipo de enfermería y, sobretodo, las enfermeras ven "subvirtiendo" a este método en su cotidiano de trabajo, en busca de una asistencia mas humanizada.

TÉRMINOS CLAVES: enfermería, método funcional

\section{REFERÊNCIAS BIBLIOGRÁFICAS}

01. ALMEIDA, M.C.P.de. A construção do saber na enfermagem: evolução histórica. In: SEMINÁRIO NACIONAL DE PESQUISA EM ENFERMAGEM, 3, Florianópolis, 1984. Anais. Florianópolis: Ed. Univ. Fed. S. Catarina, 1984. p. 58-77.
02. ANGERAMI, E.L.S.; CORREIA, F. de A. Em que consiste a enfermagem. Rev.Esc.Enfermagem, USP, São Paulo, v. 23, n. 3, p. 337-344, dez. 1989.

03. ANSELMI, M.L. Estrutura organizacional, 1989. (mimeografado)

04. ANTUNES, J.L.F. Hospital: instituição e história social. São Paulo: Letras \& Letras, 1985. 
05. BRASIL. Ministério da Educação e Cultura. Secretaria Nacional de Educação Superior \& Divisão de Hospitais de Ensino e Residência Médica. Estudos sobre o sistema de incentivo à produtividade em hospitais universitários. Brasília, 1992.

06. CAPRA, F. O ponto de mutação. 14. ed. São Paulo: Cultrix, 1992.

07. CHIAVENATO, I. Teoria geral da administração. 3. ed. São Paulo: McGraw-Hill, 1987.

08. FERRAZ, C.A. Construindo uma prática administrativa de enfermagem, 1990. (mimeografado)

09. FOUCAULT, M. Microfísica do poder. 11. ed. Rio de Janeiro: Graal, 1993.

10. HAMPTON, D.R. Administração: comportamento organizacional. São Paulo: McGraw-Hill, 1990.

11. KURCGANT, P. Administração em enfermagem. São Paulo: EPU, 1991.
12. MAFFESOLI, M. A conquista do presente. Rio de Janeiro: Rocco, 1984.

13. PAIM, L. Questões e mitos acerca de modelos de assistência de enfermagem. In: CONGRESSO BRASILEIRO DE ENFERMAGEM, 1979. Fortaleza. Anais. Brasília: MEC, Secretaria de Ensino Superior, 1979. p.61-69.

14. PATRÍCIO, Z.M. A prática do cuidar/cuidado à família da adolescente grávida solteira e seu recém-nascido através de uni marco conceitual de enfermagem de enfoque sóciocultural. Florianópolis, 1990. 282 p. Dissertação (Mestrado em Enfermagem) - Universidade Federal de Santa Catarina.

15. TREVIZAN, M.A. Enfermagem hospitalar: administração \& burocracia. Brasília: Ed. UnB, 1988. 